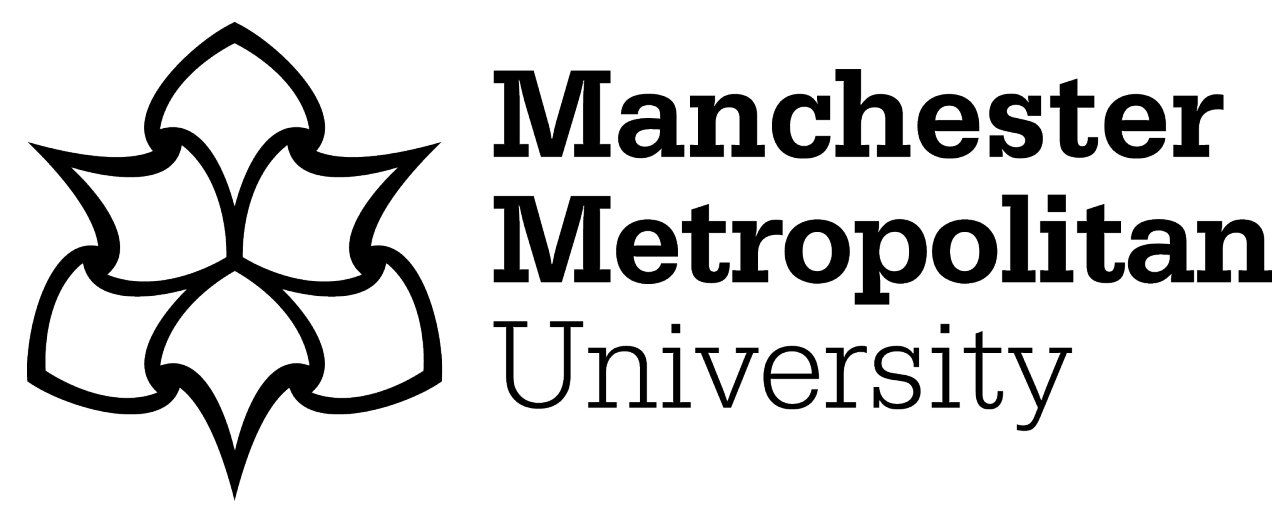

Widdop, Paul, Parnell, Daniel ORCID logoORCID: https://orcid.org/00000001-5593-0633 and Bond, Alexander (2020) Topological network properties of the European football loan system. European Sport Management Quarterly, 20 (5). pp. 655-678. ISSN 1618-4742

Downloaded from: https://e-space.mmu.ac.uk/624127/

Version: Accepted Version

Publisher: Taylor \& Francis (Routledge)

DOI: https://doi.org/10.1080/16184742.2019.1673460

Please cite the published version 


\section{Topological Network Properties of the European Football Loan System}

Alexander John Bond*, Sport Business Group, Carnegie School of Sport, Leeds Beckett University, Leeds, UK.

Paul Widdop, Sport Development Group, Department of Sport and Exercise Science, Manchester Metropolitan University, Manchester, UK.

Daniel Parnell, Centre for Sport Business, University of Liverpool Management School, University of Liverpool, Liverpool, UK.

*Corresponding Author

\section{Alexander John Bond}

215 Cavendish Hall, Headingley Campus,

Leeds, LS6 3QS, United Kingdom

Phone: $+44(0) 1138123887$

Email: $\underline{\text { A.J.Bond@,leedsbeckett.ac.uk }}$ 


\section{Topological Network Properties of the European Football Loan System}

\section{Abstract}

Research Question: Following a network perspective, we present footballs European loan system as an economic network and aim to answer the following questions; (i) what is the structure of the network? and, (ii) what are the topological properties of the network?

Research Methods: Using data on the top-5 European leagues in European football 8139 loan transactions between 31/12/2009 - 22/12/2017 were analysed using social network analysis.

Results and Findings: The results show that the loan system is embedded in ongoing structural relationships across Europe, more so in the Italian Serie A than other European leagues investigated. Additionally, our findings indicate that several elite clubs are extracting value from the loan system, while others are value creators.

Implications: The implications of this research are fourfold: recommendations for executivelevel professionals in the football industry and how to maximise the structure of the system; considerations for UEFA and FIFA policy around regulations applied to loan systems; application of economic network theory to the trading (loan) system in European football; and recommendations for future academic research.

KEYWORDS: Economic Networks, Football, Trading Systems, Markets, Social Network Analysis 


\section{Introduction}

The demand from association football (herein football) firms (clubs) for superior playing talent means expenditure has seen exponential growth; for example, expenditure on international transfers only has increased by 33\% from 2016 to \$6.37billion in 2017 (FIFA, 2018). The implications are twofold. First, smaller revenue-generating firms lack the financial capacity to compete in the transfer market to attract quality talent resources, and second, large revenuegenerating clubs can operate large player rosters, stockpiling elite and younger talent. Consequently, these two implications have meant the loan system - whereby a firm may 'borrow' a player and often gaining access to their services otherwise unobtainable - has become integral to the operation of football across Europe, and the globe.

The loan system is an integral part of a wider transfer system in place across Europe, whereby club A lends a player(s) to club B at an economic cost for a limited temporal period. If we accept the narrative that European professional sport firms are utility-maximisers, meaning profit comes second to obtaining superior talent maximizing potential win success (Caruso, Addesa, \& Di Domizio, 2019; Noll, 2002, 2003; Zimbalist, 2002), then being able to attract high-quality playing talent is fundamental to success within the football market. However, while offering an opportunity to smaller revenue-generating clubs, large revenuegenerating clubs have been accused of 'abusing' the system through the amount of stockpiling (Magowan, 2015). This narrative has led to football's global governing body Fédération Internationale de Football Association (FIFA) considering regulation on the loan system (BBC, 2018; Wiegmann, 2018). It seems, however, this decision lacks any empirical support, mainly as there is little to no empirical research on the loan system. Therefore, this paper begins to fill this gap by providing an initial analysis of the current structure of the loan system. This will 
allow football's stakeholders, particularly governing bodies, clubs, and player representatives can be better informed when agreeing to any regulations on the loan system.

To do so, we view the 'loan' as a unique temporal transaction, whereby football clubs temporarily transfer playing talent assets to another club, as such creates a transaction network within the football industry. Given the relational components of the economic transaction in the loan system, it is difficult to conceptualise it as purely theoretical adherence to neoclassical economic models. To address this, we adopt a network perspective from an economic sociology paradigm which addresses much of limitations within mainstream econometric modelling (Borgatti \& Halgin, 2011). Crucially, we follow economic sociology work by Knoke (2012), Granovetter (1985) and Burt (1992) to provide an initial descriptive analysis to understand:

1) What are the topological properties of the European loan system network?

2) Do the topological properties demonstrate a structure within the European Loan system?

The main contribution of our paper is that it provides the first analysis of the loan system operated across European football, addressing a current gap within the sport management literature. Furthermore, it contributes a novel methodology for analysing economic networks within sport management through social network analysis (SNA). Finally, it informs industry decision-makers from club management and board room executives, through to national governing bodies and footballs global governing body FIFA. Accordingly, this paper is structured by initially identifying how we conceptualise the European loan system within the sport economic literature. The network perspective will be explored to clarify our position, 
which will set up the analysis. There will be a description of the data, as well as the measures used to analyse the topological properties of the loan system. The results will be presented, which will be followed by an overall discussion, summarised with concluding remarks.

\section{Review of Relevant Literature}

\section{The Loan System}

There is a common acceptance that sport businesses, especially within professional team sports, operate differently to mainstream firms, leading Neale $(1964$, p. 1) to term the 'Peculiar Economics of Professional Teams Sports'. A central tenant to this uniqueness is the unprecedented level of collaboration and cooperation required by professional sport firms to not only create the product on the pitch but for survival off the pitch (Fort \& Quirk, 2004). This cooperative environment is more than merely just creating the 'product' (the game itself) and manifests itself through many cross-subsidisation mechanisms, which either equalise talent distribution (for example, reverse draft systems, salary caps) or revenue distribution (for example, sharing broadcasting revenue, gate receipts).

These mechanisms, regardless of focus, aim to equalise resource capacity between large and small revenue-generating sport firms. Thes mechanisms are crucial to leagues success as Quirk's (1987) classic work identified the cartel-like nature of sports leagues, with one uniqueness - sports leagues sell competition (Quirk \& Fort, 1995). This notion of selling competition, or what Rotternberg (1956) termed uncertainty-of-outcome, led to competitive balance becoming a prominent theoretical construct in the management of professional team sports literature (Kringstad, 2018; Schreyer \& Torgler, 2018). Research on competitive balance - which identifies how well playing talent quality and financial strength is distributed between teams in a league (Owen \& King, 2015; Ramchandani, Plumley, Boyes, \& Wilson, 2018) - has 
been dichotomously categorised into, analysis of competitive balance (ACB) and uncertaintyof-outcome hypothesis (UOH) research (Fort \& Maxcy, 2003). It is the former ACB body of literature that deals with the cartel-like nature of sports leagues, investigating the impact of market restrictions imposed by leagues on competitive balance.

Generally, sports leagues either impose regulations on the distribution of talent (such as the draft system operated across North American sports) and/or money (such as revenue sharing/pooling agreements). Accordingly, a large body of research has focussed on the draft system, salary caps and/or revenue sharing systems such as gate receipts or broadcasting revenues (Dietl, Grossmann, \& Lang, 2011; Dietl, Lang, \& Rathke, 2011; Feess \& Stähler, 2009; Hill \& Jolly, 2017; Peeters, 2015; Rockerbie \& Easton, 2018; Szymanski, 2016; Szymanski \& Kesenne, 2004; Wilson, Ramchandani, \& Plumley, 2018; York \& Miree, 2018). However, within a European context, no scholarly work to date has gone beyond financial distribution cross-subsidisation mechanisms. Which is interesting as there exists a much larger embedded cross-subsidisation mechanism operated across global football, often driven by European leagues, the loan system.

While there is little to no known research on the loan system, we can take the basic principle, that is, higher revenue-generating firms supporting the lower revenue-generating firms, as such loan system, can and should be considered a cross-subsidisation mechanism employed across the global football industry. For example, the loan system generally operates with football firms with large resource capabilities 'loaning' players (resource) to firms with smaller resource capabilities - either domestically or internationally (Simmons, 2007). Often, but not always, clubs with larger rosters (resource capabilities) represent larger revenuegenerating clubs, and smaller rosters represent smaller revenue generating clubs.

Indeed, this system has become more established and sophisticated, going from a more flexible system to assist clubs with injury problems or to support opportunity for talent 
development, to a strategic business strategy through to strategic alliances and value generation. Indeed, to some degree, this system can be considered pareto improvement as it benefits both lending club - the player receives experience and playing time, potentially increasing resource value - and, borrowing club - as they utilise the services of the resource for the duration of the loan, which would have been inaccessible, theoretically improving the firm's output (team performance) and potentially win success, temporarily. Therefore, such a system provides opportunities for firms to develop official and unofficial collaborations, as it essentially operates as a "contractual asset pooling or resource exchange agreement between firms" (Stuart, 1998, p. 668). It is our position that these collaborations that make the firms (clubs) in the football industry interlinked creating patterned dyad and triad connections, and in the process forming what Salancik and Pfeffer (1978) note networks of pipes through which flow information and resources. It is this web of temporal transactions context we draw on network theory to explore and analyse much-needed insight into the characteristics of the loan system.

\section{The Network Perspective}

Economic sociology focusses on the structure of economic action through networks (Burt, 1992; Granovetter, 1985, 2005). To follow Knoke's (2012, p. 15) operational definition: "economic sociology is the use of sociological ideas to analyze economic phenomena", we argue that the loan system within Europe is an economic phenomenon, which can be - and should be - analysed through the economic sociology paradigm. Therefore, to analyse these structures of loan transactions, we adopt a network perspective, which has developed from economic sociology (Chayko, 2015). Underpinned by social network analysis (SNA) this perspective cuts across many social science disciplines, including; biology, physics, management consulting, public health, criminology (Borgatti, Everett, \& Johnson, 2018; Scott, 
2017; Wasserman \& Faust, 2009). Therefore, it is a multidisciplinary perspective that places structure at the centre of any analysis of human and economic life, as identified by (Knoke, 2012, p. 21);

The web of ties among actors in a social system comprises the larger contexts that affect the perceptions, beliefs, attitudes and actions of individuals and groups. Social influence and collective action may be both facilitated and constrained by direct and indirect transactions among actors possessing diverse resources, such as information, money, authority, and power.

Knoke's inspiration comes from seminal work by Granovetter (1985), which not only paved the way for the 'new' economic sociology but placed networks as the key to economic activity.

Furthermore, Granovetter (1985) laid out a theory of embeddedness, stipulating how economic behaviour is embedded structurally and relationally in relationships. As such, all economic behaviour is rooted and embedded in social relations, meaning economic behaviour, such as sharing assets through the loan system, is structured - influenced by social interactions and relationships. Therefore, embeddedness works on the premise that economic actors (players, clubs, countries, federations) are impacted by; connections to others, their position they occupy in the wider structure, and, by the structure of the overall network. Indeed, such an idea is contrary to the neo-classical frameworks dominant in economics (Dacin, Beal, \& Ventresca, 1999; Dobbin, 2004; Granovetter, 1992) especially sport economics, which is based on utility maximisation and rational atomised actors, favouring placing greater emphasis on how position and structure constrain behaviour.

Granovetter (2017) identified four theoretical frameworks that underpinned his formulation of embeddedness. Firstly, the idea of density and cohesion, whereby norms of conventions (for example trust) and shared ideas and behaviour are impacted upon by the size, 
density, and how cohesive the network structure is. Second, the strength of weak ties, while strong ties reinforce trust and bonding, new information and innovation come from weak ties who tap into other areas of the structure. Third, Ronald Burt's (1992) theory of 'structural holes', which notes the importance of the position of an actor (corporate or human) in a network - especially concerning the advantage that it can create. For Burt, individual or organisations with ties into multiple networks that are otherwise unconnected enjoy a competitive and strategic advantage. In such a situation, the said actor spans what Burt calls a structural hole, thus controlling what is flowing through the network. Being in such a strategic potion allows them to exploit the structural hole in the networks they join (Burt, 1992). Individuals are effectively brokers and can thus leverage and trade-off what is flowing, be it money or information. Finally, temporal embeddedness, which suggests transactions or interactions have a past, that is, all micro-interactions form to generate the global structure, if this structure persists over time it may come to represent an institution, this global structure then impacts back upon the present and future interactions. Consequently, it is our view that the European loan system is based on temporal transactions in a structure, providing a testbed for analysis through a structural network perspective, focusing on the duality of structural and relational embeddedness.

\section{Networks and Sport Management Research}

There is a developing body of literature applying network thinking principles and social network analysis since Quatman and Chelladurai (2008a, 2008b) set forth a research agenda for sport management scholars. Given the multidisciplinary nature of social network analysis and the sport management discipline, this body of research covers a wide range of topics ( $c f$. Hambrick, 2019, for a full review). Two recent popular topics are sport performance (Lusher, Robins, \& Kremer, 2010) and social media (Hambrick, 2019). Within sports performance the topics remain very broad, for example, Fransen et al. (2015) applied social network analysis to 
investigate shared leadership within sports teams, concluding no difference in coach and athlete leaders, yet the latter were perceived to be more motivational leaders. Contrastingly, Beggs, Shepherd, Emmonds, \& Jones (2017) applied network theory, notably the PageRank algorithm, to rank athlete performance. The works on social media are less broad and tend to focus on Twitter networks (Hambrick, 2012; Naraine \& Parent, 2016; Yan, Pegoraro, \& Watanabe, 2018; Yan, Watanabe, Shapiro, Naraine, \& Hull, 2018). Analysing the Twitter networks of two sports organisations, Naraine and Parent (2016) applied Bonacich (Beta) centrality and core/periphery analysis to identify the prominent/critical stakeholders in the networks.

Similarly, Yan et al. (2018) analysed the UEFA Champions League Final twitter discovering large sporting enterprises and sports stars were integral to the network formation and stability throughout its evolution. Comparably, Cleland, Doidge, Millward and Widdop's (2018) found similar results analysing the collective action within Liverpool Football Club fans while protesting ticket prices. While noting the importance of these works to the development of the sport management literature applying social network analysis, and thus arguably, implicitly economic sociology, the relevance to the present study is limited.

More relevant sport management literature applying social network analysis focusses on sport organisation networks (Jones, Edwards, Bocarro, Bunds, \& Smith, 2018; Sallent, Palau, \& Guia, 2011; Wäsche, 2015; Wäsche \& Woll, 2013). For example, Sallent et al. (2011) identified the importance of inter-organisational and cross-sectoral weak ties to the success of sports events as well as the role embeddedness plays in delivering a successful event, implicitly supporting Granovetter's (1983, 1985) work. Equally, Wäsche (2015) found, among other things, that inter-organisational cooperation was more likely with organisations in a closed triad, demonstrating how embeddedness creates trust among organisations, again implicit support for Granovetter's $(1985 ; 2017)$ work. The most relevant work within sport management literature is those using network theory to investigate the transfer market (Bond, 
Widdop \& Chadwick, 2018; Liu, Liu, Lu, Wang \& Wang, 2016). Especially, Bond, et al. (2018) who explicitly applied economic sociology principles to the transfer network of emerging countries within world football. They found that European countries act as brokers between the emerging countries, deriving power through an advantageous position. Nevertheless, the present study focuses on a different form of economic transaction to football transfers by analysing loan transactions between football clubs. Therefore, not only does it add the first empirical article to investigate the loan system within football, but it also adds to the growing body of sport management literature applying social network analysis through an economic sociology theoretical framework.

\section{Methodology}

Before establishing the methodological process employed in this research, social network analysis requires a boundary to be first established (Borgatti \& Halgin, 2011). Following the nominalist view (Knoke \& Yang, 2008), the boundary for the European loan network compromises of the top-5 European leagues according to Deloitte (2018), which are England's Premier League, Spain's La Liga, Germany’s Bundesliga, Italy’s Serie A, and French's Ligue 1. The data gathered for this study included 8139 loan transactions involving clubs in the respective leagues from $31 / 12 / 2009-22 / 12 / 2017$, which was all available data at the time of data collection. As we are only interested in loan transactions, we do not account for permanent transfers, free agent moves, length of the loan, a player returning from loan, or whether a loan deal is cut short. We are only concerned with the initial engagement between club A and club B within the loan transaction. Following Liu, et al. (2016) and Bond, et al. (2018) data was initially sourced from www.soccerway.com, which is operated by Opta Sports Limited who provide data to key organisations throughout the industry. For robustness and to validate the 
data, we cross-examined with other data sources such as www.transfermarkt.com, as well as official club sites.

Utilising social network analysis methodology employed in this study requires a brief explanation of graph theory, which became the bedrock of social network analysis after Cartwright and Harary's (1977) work. A graph (or network) describes a set of nodes (or vertices, or actors) which are connected through a set of edges (or ties, or links). These edges connect nodes through an array of interactions and/or relationships (For a more in-depth introduction to social network analysis see; Vega-Redondo, 2007; Wasserman \& Faust, 2009). The notation within graph theory follows $G=(V, L)$, identifying that graph $G$ is comprised of a set of nodes, $V$, and a set of edges, $L$, or $L \in V \times V$ (Wasserman \& Faust, 2009). Within the European loan network of 8139 collective loans under investigation we identify $n=1105$ nodes (football clubs) involved within the loan system, thus $V=(1,2,3, \ldots, 1105)$, with 5331 unique edges (loan connections) between them, thus $L=(1,2,3, \ldots, 5331)$. Note the edges within the network is less than the observed loan transaction, suggesting 2808 were between clubs with a pre-existing loan partner.

As the edges within the study follow the direction of the loan deal from a lending club, $i$, to a borrowing club, $j$, these are often termed arcs transforming the graph into a digraph simply a directed graph (something flows from one point to another, but may or may not be reciprocated). As such, $L_{i j} \in\{0,1\}$, where $L_{i j}=1$ showing a loan relationship and $L_{i j}=0$ where a loan relationship does not exist. This is represented in an asymmetric $n \times n$ adjacency matrix, A. This means a loan relationship is not assumed between $L_{j i}$ just because of the loan relationship between $L_{i j}$.

We can also weight the arc to account for the number of times loan deals are made between two clubs, which creates a weighted digraph, and can be noted as a network $N=(G$ 
$(V, L), W, P) . W$ represents edge characteristics; in this instance, the number of loan deals between two clubs and $P$ identifies node information, such as the club name. Additionally, $P$ will capture the exogenous information such as local metrics associated with the topological properties of the nodes (clubs) within the loan network structure. To analyse the topological properties of the global and local structure, the 'sna' (Butts, 2016) and 'tnet' (Opsahl, 2009) packages in R, and the UCINet programme (Borgatti, Everett, \& Freeman, 2002) were utilised. Network visualisations were created in Gephi (Bastian, Heymann, \& Jacomy, 2009). The following network measures were applied (the mathematical notation and technical details of these measures are in the online supplementary information);

\section{Global Measures}

Average Degree - The most straightforward network measure is merely the number of connections a node has in a network or degree. Once worked out at an individual level, it can be averaged to provide a global metric comparable to other networks. In this case, the average degree demonstrates the number of loan partners a club has been involved.

Weighted Average Degree - By weighting the degree, this tells us the number of individual loan transactions a club has been involved. Therefore, similar to average degree, it can be averaged out over the whole network to provide a comparative global metric. Here it demonstrates the average number of loans a club has been involved in within the network.

Density - Perhaps the most communally used measure of global network properties of a structure in network theory is density. Graph density measures "...overall level of connectedness in a network" (Scott, 2017, p. 81). By measuring density, we compare the actual number of links present to that of a complete graph - where all nodes are connected. This measure provides a value between 0 and 1; 0 where no nodes are connected and 1 where all 
nodes are connected (complete graph). In this instance, it tells us how connected the European loan network is.

Global Clustering Coefficient and Transitivity - Density is generally only concerned with the dyadic relation between two nodes, that is, how many edges are present in a network and gives us a fundamental measure. The global clustering coefficient, often referred to as transitivity, extends this measure encapsulating the density of triadic relations within the network by analysing the density of triplets. A triplet consists of three nodes either connected by two (open triplet) or three (closed triplet) edges, and a triangle consists of three closed triplets. The global clustering coefficient based on Luce and Perry (1949) original work, measures the number of closed triplets over the total number of triplets present in the whole network (both open and closed). However, the global clustering coefficient does not account for the weight of connections, leading Opsahl and Panzarasa (2009) to generalise the global clustering coefficient for weighted networks by taking the total value of closed triplets. In both instances, these measures provide the same output $0-1,1$ identifying all triplets are closed, and 0 representing an unconnected network.

Triad Census - The global clustering coefficient measures transitivity by comparing only two types of triadic relations, open and closed. However, there are numerous other combinations of triadic relations. In fact, Wasserman and Faust (2009) identify 16 different configurations following Holland and Leinhardt (1976) MAN convention. MAN stands for Mutual - number of reciprocated ties, Asymmetric - number of unreciprocated ties and Null number of no ties. Therefore, to better understand the global structure of the loan system, we also need to understand all the configurations of triads, above and beyond merely open and closed. Figure 1 demonstrates the multiple configurations, with 030T, 120D, 120U, 300 types demonstrate transitive configurations, meaning each node in the triad shares resources with one another. Based on these configurations, Batagelj and Mrvar (2001) developed a 
sophisticated algorithm to count the number of times each configuration is present in the network, providing a count for each configuration.

\section{[Figure 1 Here]}

\section{Local Measures}

While it is essential to understand the global structure of the European loan network, local measures can provide more insight into the roles and positions of individual clubs within the network. The most common endogenous network properties are those associated with centrality, which is central within the network and has access to more resources and information. Generally, there are four primary metrics, which measure how central a node is within the network, or how central a club is within the loan system in this instance. The four common metrics are;

Degree centrality - measures the connectedness of a node - or the number of loan partners a club has within the loan network. Generally, those with more connections are more powerful than those with fewer connections as they influence many rather than the few (Newman, 2010). As the metric is based on the number connections, a node has, and for better interpretation of results, it can be normalised to the whole network. Within a directed network, there are two measures of degree centrality; in-degree - the number of arcs pointing into a node, and, out-degree - the number of arcs exiting a node. Therefore, in-degree for the European loan network represents the total number of football players borrowed by a club, and, out-degree shows the total number of football players loaned by a club.

Closeness centrality - refers to the topological distance, or how close a node is to all other nodes based on the steps required for node $i$ to reach node $j$, often termed geodesic 
distance. This is the shortest path between two nodes, and the inverse average geodesic distance of a node provides a proximity score, higher-scoring nodes are more central within the network. Similar to degree centrality, within a directed network there are two different aspects of closeness, in- and out-, therefore, the geodesic distance for node $i$ and $j$ may differ depending on the nodal order. Therefore, we calculate in-closeness ( representing clubs receiving players) and out-closeness (representing clubs providing players).

Betweenness centrality - shows a node's importance through connecting unconnected nodes - or a clubs that sit between two unconnected clubs, which is a basic measure for Burt $(1992,2004)$ structural holes. Following the idea of geodesic distance, betweenness centrality measures a node's centrality based on how many times a node is present on the geodesic path between unconnected nodes $j$ and $k$. Since node $i$ sits between two unconnected nodes $j$ and $k$, this provides node $i$ an advantaged position and thus strategic implications. The betweenness centrality measure represents the proportion of geodesic distances $i$ is involved in throughout the network (Vega-Redondo, 2007).

Beta centrality - also known as, Bonacich centrality or Bonacich power (Bonacich, 2007), identifies the influence and importance of a node through its neighbours - or how powerful a club is depending on the centrality of its loan partners ( $c f$. Jackson, 2008). Similar to Burt's focus on the degree of a node's alters, (Bonacich, 1972b, 1972a, 1987, 2007) proposed measures of centrality using the degree of a node's alters. Here, power is derived by being connected to well-connected others (power) or being connected to poor-connected others (dependency). Assigning a positive parameter measures 'power' - power comes from influential friends, whereas, a negative parameter measures 'dependency' - power comes from weak friends as they are more dependent on the relationship.

\section{Results}


The full loan network has been mapped in Figure 2, and the measures are presented in Table 1. The density of the loan system is 0.007 , that is only $0.007 \%$ of possible ties are present. This suggests the loan system represents a sparse network compared to a complete network, suggesting clubs only enter into a loan agreement with relatively few clubs. The global clustering coefficient is 0.158 , suggesting $15.8 \%$ of triplets are closed. This points to clubs working together to share talent resource (players). Furthermore, when the weight of ties is incorporated, the generalised global clustering coefficient is higher at 0.196 or $19.6 \%$ of triplets being closed, demonstrating clubs who belong to a closed triplet share more resource, id est, clubs loan multiple players to the same clubs, or what is known as transitivity.

However, the clustering coefficient does not identify the make-up of the closed triplets, that is, the different combinations of mutual, asymmetric and null ties. The triad census results show there is a tendency for the closed triplets to be transitive with transitive combinations 030T, 120D, 120U and 300 (see Figure 1), being the majority of the triads within the network. This identifies a hierarchy within the network, specifically the 030T (7776) and the 120U (1495) types. Interestingly, forty 300 types exist, implying there are 40 cliques within the network. This is an important finding as it demonstrates a specific structure to loan transactions, which shows the mutual sharing of talent resource. The implication here is various clubs working together mutually sharing talent resource, indicative of a strategic alliance between competing clubs.

\section{[Table 1 Here]}

[Figure 2 Here]

The results presented in Table 2 show the structure of the loan system within each European league under investigation. The density of each is relatively comparable, which is 
mainly due to the sensitivity of the number of clubs involved in each network. Nevertheless, each league has sparse connections to the number of clubs within the network. The Premier League and Serie A have very similar topologies, both having $>3$ average degree, meaning each club on average has three loan partner clubs. Similarly, they both have similar weighted average degree $>6$, suggesting on average each club is involved in 6 loans. Unlike Bundesliga, La Liga and Ligue 1 who have $<3$ loan partners, and loan $<3$ players on average, except for Bundesliga who loan approximately 4 on average. The global clustering coefficients are all comparable suggesting between $9 \%-10.1 \%$ of triplets in each network are closed. However, Serie A is far more clustered than any of the other European leagues with $24.4 \%$ of the triplets closed within the network. This is a peculiarity suggesting that clubs are sharing much more playing talent through the loan system within Italy than across Europe. When we account for the generalised global clustering coefficient only the Premier League demonstrate a higher score, suggesting a tendency for clubs to share more playing talent when they belong to a closed triplet, rather than an open triplet - or, they loan more players to clubs who are also interconnected.

\section{[Table 2 Here]}

The local measure analysis broke the network down even further and looked to analyse the position clubs take within the network.

\section{Degree Centrality}

The results for degree centrality are presented in Table 3 for out-degree centrality (lending players), and Table 4 for in-degree centrality (borrowing players). Analysing the outdegree centrality of clubs (Table 3.), it is evident that a few clubs are capitalising on the loan system by lending exponentially more players, namely Juventus (Italy) $(=0.012)$, Atlanta (Italy) $(=0.009)$, and Chelsea (England) $(=0.009)$. Furthermore, over the period analysed, 
Juventus have engaged in 358 loan agreements to 135 different clubs, which is substantially more than Chelsea who has engaged 263 loan agreements, but across 139 different clubs which is a different strategy to the other network voracious loaner, Juventus. This is somewhat contrary to clubs who receive loan players (Table 4.), as 17 clubs generally have similar normalised in-degree scores $(=0.02)$. However, certain clubs take loan players from a wider dispersion of clubs, such as Deportivo (Spain), Huddersfield (England), and Hellas Verona (Italy), lending players from 34, 32 and 31 different clubs respectively. More generally, based on in-degree centrality, it is clear there is a propensity for Italian clubs to engage in loan agreements, both lending and borrowing playing talent. Specifically, three Italian clubs dominate the loan system considering both giving and receiving players: Genoa, Chievo and Roma.

\section{[Table 3 here]}

\section{[Table 4 here]}

\section{Closeness Centrality}

The results for closeness centrality are presented in Table 5. Similarly to degree centrality, there is a clear tendency for lending clubs to be more central, thus, influential within the network. Individually, Chelsea has the greatest access to the network $(=.394)$, showing they occupy the shortest paths of $39.4 \%$ of connections throughout the European loan network. Moreover, compared to degree centrality, we start to see the emergence of Europe's high performing clubs, with England's Manchester City, Liverpool and Arsenal, along with Spain's Barcelona, Real Madrid and Atletico Madrid all having considerable access to resources in the network. Interestingly, Spain's emergence is also apparent within the in-closeness scores, showing they are well connected within the loan network and can access loan providers. Again, Italy is utilising the loan system more than other European leagues, as clubs such as AC Milan, 
Genoa, Inter Milan and Roma all having influential roles both lending and borrowing playing talent.

\section{[Table 5 here]}

\section{Betweenness Centrality}

The results for betweenness centrality are presented in Table 6. Roma's apparent influential position is emphasised when considering those clubs in the network that connect otherwise unconnected clubs, with a betweenness centrality score $=2.707$. While the expected Italian clubs (Juventus, Genoa, AC Milan, Chievo, Hellas Verona and Inter Milan) hold advantageous positions, interestingly Chelsea does not. Instead, English clubs Watford, Swansea and West Ham occupy more advantageous positions. Furthermore, Monaco (France) can draw power from the loan network through betweenness, which until now has gone unnoticed.

\section{[Table 6 here]}

\section{Beta Centrality}

The results for beta centrality are presented in Tables 7 and 8. Firstly, understanding power based on the notion that being connected to well-connected others derives power, we assigned a positive parameter $=0.0403619$. Taking this view of deriving power from others, Udinese and Inter Milan (Italy) are connected to the strongest others concerning lending players. Again, Italian clubs are extremely interconnected - as seen in Graph 1 - evidences the structural embeddedness of the loan system within Italian football. Furthermore, English clubs Chelsea, Manchester City and Arsenal, are drawing power through their loan strategy, lending to other central clubs. Indeed, in-degree beta centrality further reinforces the embeddedness of the loans system within Italy, with the most central clubs borrowing players all being Italian. 
However, taking the view that power is derived by lending players to clubs who are not well connected - or the dependence view - the results differ. Here we assigned a negative parameter $=-0.0403619$. Firstly, considering lending players, Juventus still demonstrate their integral dominance in the loans market, not only being the most active lending players to already well-connected clubs, but they also connect poorly-connected club, meaning they are 'dependent' on the relationship with Juventus. Moreover, English clubs are dominant, which could demonstrate lending players out strategically, meaning they have power through dependence. In terms of borrowing players from weakly connected clubs, Deportivo top the list across Europe. Interestingly, smaller clubs from England move up in terms of dependency power, such as Brighton and Hove Albion, West Ham, Watford, Huddersfield and Leicester. These are all clubs who have been promoted to top-flight English football, so potentially are at the start of developing their loan network. Importantly, Roma also has a high dependency score, reinforcing their strong position in the loan network across Europe. Interestingly, Chievo can derive considerable dependence power from the loan system by lending and borrowing players to/from relatively unconnected clubs, meaning both their lending and borrowing partner clubs are dependent on their relationship with Chievo. To that end, they represent some kind of low stakes broker connecting unconnected parts of the network (Burt, 1992).

\section{[Table 7 here]}

\section{[Table 8 Here]}

\section{Discussion}

By conceptualising the European loan system as a cross-subsidisation mechanism, we can analyse the resource flow of playing talent, which adds to the literature on market restrictions within European sport (Szymanski, 2016; Szymanski \& Kesenne, 2004; York \& Miree, 2018; Wilson, Ramchandani \& Plumley, 2018). Additionally, this research has applied a novel 
approach to sports management research by using social network analysis to analyse the economic networks created by the European loan system, thus, also adds to the economic and social network literature (Knoke, 2012; Burt, 1992; Granovettor, 2017).

The findings from understanding the global whole network characteristics suggest support for Granovetter's $(1985,2017)$ argument that trust is required within any economic transaction, as the largest triad configurations are closed triplets. This demonstrates that loan agreements are entered into by interconnected clubs, and the more interconnectedness, the more loan agreements between clubs. This finding is also similar to Wäsche's (2015) work concluding more cooperation between organisations in closed triads. This may be a result of a loan agreement requiring a level of trust - the receiving club trust that the talent will be adequate playing standard, and the loaning club trust the receiver will provide enough support and development. Again, this aligns to Granovetter's conjecture that trust in a network leads people to co-operate and otherwise act more benignly towards one another. This co-operation saves substantial costs of precaution and monitoring that would be expended without it - or in this instance, saves time entering into ineffective loan agreements.

Furthermore, the implication of transitivity in the network means clubs tend to loan more players to those clubs in their closed group. This could demonstrate the strategic nature of the loan system; a strategy based on relationships rather than based on rational or random choices. Additionally, clubs need to strategise their loan policy and practice to ensure a position within the network. Furthermore, it could allude to peer-effects within the loan system, whereby loan transactions of one club are effected by another club. However, further research is needed to identify the role of peer-effect within the loan system specifically.

Analysing the local position and the role each club plays within the loan system demonstrates the cross-subsidising nature of the loan system, with those occupying powerful positions loaning players out being higher revenue-generating clubs, and those occupying 
influential positions receiving loans lower revenue-generating clubs (Simmons, 2007). Furthermore, the local node level analysis demonstrated a considerable level of embeddedness within the Italian loan system. Suggesting the loan marker in Italy is not necessarily bound by utility maximisation principles, but actors are deeply interconnected, which will undoubtedly impact behaviour and access to information (Granovetter, 2017; Knoke, 2012). Additionally, powerful actors in this market will become sources of power through preferential attachment (Bonacich, 1987; Scott, 2011).

The loan system is a fundamental part of Italian football, which is demonstrated by the consistent dominance within the results. Although this probably reflects the local loan agreement policies operated by the Italian Football Association, the implications are that Italian clubs are central to the European loan system. Therefore, any changes to regulations enforced by football governing bodies could affect Italian football clubs exponentially more than any others across Europe.

There are some clubs in very exploitable positions, mainly Juventus who regardless of the conceptualisation of power (strong or weak connected friends; Bonacich, 1987), consistently occupy a position of advantage (Burt, 1992). They structurally positioned within a 'structural hole' as they consistently connected multiple networks that are largely separated from one another. Therefore, they enjoy a strategic advantage (Burt, 1992; Granovetter, 2017). As a result, Granovetter (2017) notes that individuals in these situations can be effective brokers and thereby enjoy substantial social capital. This means they can extract the most value from the system.

While other clubs are clearly well embedded and powerful within the network - such as Chelsea FC, Roma, AC Milan, Inter Milan, Manchester City to name a few - none are as dominant as Juventus. Especially as they not only supply clubs which have many other 
connections - or power (Bonacich, 1987) but also supply those with few connections dependency (Bonacich, 1987). Showing they supply talent resource to other clubs who are in powerful positions in the network, as well as providing players to clubs in weak network positions. The latter is an essential consideration as changing regulations on loan agreements could have detrimental effects to those poorly positioned clubs who are reliant on loan agreements with well-connected suppliers of resource, such as Juventus. While regulation to limit the influence of dominant clubs in the loan market may be the desired goal, without reflecting on the network structure they may merely add to the difficulties of the smaller clubs they are trying to protect.

Interestingly, while many clubs extract value from the network - mostly the high revenue-generating clubs - numerous clubs are creating value within the system. These are clubs who take loan players and have strategic positions by doing so. For example, Spanish clubs Deportivo and Granada, along with English clubs Brighton \& Hove Albion, Watford and Huddersfield, join Italian clubs, Genoa, Hellas Verona, Roma and Fiorentina in the most strategic positions, as these all receive playing talent from clubs who are not well connected, therefore are reliant on them to loan players to, creating their own power (Bonacich, 1987). Additionally, Juventus again occupy an advantageous position in terms of borrowing players, suggesting they have established a strategy on both sides of the loan system. Therefore, they clearly understand the importance of the structural position, developing a talent policy to reflect not only providing players to clubs but also taking players.

\section{Implications}

This paper begins to fill this gap by providing an initial analysis of the current structure of the loan system, meaning football's stakeholders, particularly governing bodies, clubs, and player representatives can be better informed when managing, operating or regulating the loan 
system. The implications of this research are fourfold: recommendations for executive-level professionals in the football industry and how to maximise the structure of the system; considerations for UEFA and FIFA policy around regulations applied to loan systems; application of economic network theory to the trading (loan) system in European football; and recommendations for future academic research.

Based on the findings within this study, executive-level professionals need to understand the (un)intended consequences of engaging in loan agreements; either as a talent resource supply or talent development initiative. For example, loaning a player to a club who has limited connections can offer a dominant position as they are reliant on the talent resource. Similarly, borrowing a player from a club with limited connections can provide the same advantageous position. Therefore, club executives need to understand their network when considering engaging in loan agreements. Primarily, we recommend clubs should have a strategy regarding loan agreements as well as consider employing a loan manager to manage such transactions, much like the model employed by Juventus.

Likewise, since football's governing bodies such as FIFA and UEFA are currently considering regulating the loan system, they also need to understand the consequences of doing so entirely. While this research does not explicitly investigate the consequences of regulation; it does provide useful insight for governing bodies and league management. For example, the negative beta centrality results in Tables 8 indicate those clubs who are dependent on their relationships through loans for talent supply. Consequently, regulating the loan system may negatively affect those who are more dependent on loans such as Deportivo, Brighton \& Hove Albion and Granada, among others. Indeed, consideration also needs to be given to those clubs who are dependent on supplying talent, which is most Italian clubs, specifically Juventus, Atlanta, Chievo and Sampdoria. Indeed, football's governing bodies, technical directors and individual club sporting directors must be cognizant that while a strategy is needed regarding 
player loans; it also needs to be contextualised around broader club level implications on talent pathways, such as blocking players transitioning from the academy to the first team.

We have shown how the loan system can be contextualised as a cross-subsidisation system, much like others operating across global professional sport, such as draft systems and revenue sharing agreements. However, it provides some distinct nuances which need to be explored fully. By applying economic network theory, we have provided the first descriptive analysis of how the loan system is structured and been able to identify the critical clubs involved in the flow of playing talent through the system. Further research is required to understand implications of position in the network, answering questions such as; does an advantaged network position lead to better performance (both financially and 'on-field')? Are loan transactions of clubs influenced by the loan transactions of others? How do other regulations such as Financial Fair Play (FFP) influence the behaviour of clubs in the loan network?

\section{Conclusions}

This is the first research to conceptualise the loan system within European football as a crosssubsidisation mechanism, similar to other market restrictions such as revenue sharing, draft systems and salary caps. By taking this view, we can map the flow of resource through network analysis. This paper has presented the European loan system as a resource-sharing network by taking the top-5 European leagues (English Premier League, Spanish La Liga, Italian Serie A, German Bundesliga, and French Ligue 1) as the network boundary. This has provided some insightful description of the structure the loan system creates, from a global whole-network approach it shows clubs tend to share more playing resource with clubs they trust, or clubs who are in a closed triad. 
From a local individual club level, it identifies how the loan system is more embedded within individual leagues, specifically the Italian Serie A. While potentially reflecting unstandardised loan agreement practices across Europe, it highlights a high level of cooperation and collaboration within Italian football, more than any other European league. Furthermore, it shows the exploitive position large revenue-generating clubs have, especially Juventus whose power and influence goes beyond the mere volume of players loaned out, ultimately they have strategised the loan system. However, this research does not go beyond describing the loan system's dynamics; therefore, further research should aim to ascertain the implications that network positions have on organisational, financial and team performance.

Notably, interpretation is somewhat limiting due to the static nature of social network analysis. Hence, without comparison, it is hard to establish whether the findings are different from what would be typically or theoretically expected. Therefore, future work should look at exponential random graph models or longitudinal (dynamic) network analysis to establish consequences of network position. Additionally, sports economists should treat the loan system as a cross-subsidisation mechanism and provide the same level of analysis and scrutiny other mechanisms have received. Further research is also needed to understand the potential impacts of any regulation changes to the loan system, especially on the smaller revenue-generating teams who are reliant on the loan system. Finally, specific network research identifying equivalence, peer-effects, and, performance-related implications of the loan system would further this work.

\section{References}

Bastian, M., Heymann, S., \& Jacomy, M. (2009, May 17 - 20). Gephi : An Open Source Software for Exploring and Manipulating Networks Visualization and Exploration of Large 
Graphs. Paper presented at The Third International AAAI Conference on Weblogs and Social Media. https://www.aaai.org/ocs/index.php/ICWSM/09/paper/view/154/1009

Batagelj, V., \& Mrvar, A. (2001). A subquadratic triad census algorithm for large sparse networks with small maximum degree. Social Networks, 23(3), 237-243. https://doi.org/10.1016/S0378-8733(01)00035-1

BBC. (2018). Fifa agrees to limit loan deals and re-introduce agent regulation - BBC Sport. Retrieved January 10, 2019, from https://www.bbc.co.uk/sport/football/45643965 Beggs, C. B., Shepherd, S. J., Emmonds, S., \& Jones, B. (2017). A novel application of PageRank and user preference algorithms for assessing the relative performance of track athletes in competition. PLoS ONE, 12(6), 1-26. https://doi.org/10.1371/journal.pone.0178458

Bonacich, P. (1972a). Factoring and weighting approaches to status scores and clique identification. The Journal of Mathematical Sociology, 2(1), 113-120. https://doi.org/10.1080/0022250x.1972.9989806

Bonacich, P. (1972b). Technique for Analyzing Overlapping Memberships. Sociological Methodology, 4(May), 176-185. https://doi.org/10.2307/270732

Bonacich, P. (1987). Power and Centrality: A Family of Measures. American Journal of Sociology, 92(5), 1170-1182. https://doi.org/10.1086/228631

Bonacich, P. (2007). Some unique properties of eigenvector centrality. Social Networks, 29(4), 555-564. https://doi.org/10.1016/j.socnet.2007.04.002

Bond, A. J., Widdop, P., \& Chadwick, S. (2018). Football's emerging market trade network: ego network approach to world systems theory. Managing Sport and Leisure, 23(1-2), 70-91. https://doi.org/10.1080/23750472.2018.1481765

Borgatti, S. P., Everett, M. G., \& Freeman, L. C. (2002). Ucinet for Windows: Software for 
Social Network Analysis. Harvard, MA: Analytic Technologies.

Borgatti, S. P., Everett, M. G., \& Johnson, J. C. (2018). Analyzing social networks (2nd Edition). London: SAGE Publications Ltd.

Borgatti, S. P., \& Halgin, D. S. (2011). On Network Theory. Organization Science, 22(5), 1168-1181. https://doi.org/10.1287/orsc.1100.0641

Burt, R. S. (1992). Structural holes: The social structure of competition. Cambridge, MA: Harvard University Press.

Burt, R. S. (2004). Structural Holes and Good Ideas. American Journal of Sociology, 110(2), 349-399. https://doi.org/10.1086/421787

Butts, C. T. (2016). sna: Tools for Social Network Analysis. R package version 2.4. Retrived from https://cran.r-project.org/web/packages/sna/sna.pdf

Cartwright, D., \& Harary, F. (1977). A graph theoretic approach to the investigation of system-environment relationships $\dagger$. The Journal of Mathematical Sociology, 5(1), 87111. https://doi.org/10.1080/0022250X.1977.9989866

Caruso, R., Addesa, F., \& Di Domizio, M. (2019). The Determinants of the TV Demand for Soccer: Empirical Evidence on Italian Serie A for the Period 2008-2015. Journal of Sports Economics, 20(1), 25-49. https://doi.org/10.1177/1527002517717298

Chayko, M. (2015). The first web theorist? Georg Simmel and the legacy of 'The web of group-affiliations.' Information, Communication \& Society, 18(12), 1419-1422. https://doi.org/10.1080/1369118x.2015.1042394

Cleland, J., Doidge, M., Millward, P., \& Widdop, P. (2018). Collective action and football fandom : a relational sociological approach. London: Palgrave Macmillan.

Dacin, M. T., Beal, B. D., \& Ventresca, M. J. (1999). The embeddedness of organizations: dialogue \& directions. Journal of Management, 25(3), 317-356. https://doi.org/http://dx.doi.org/10.1016/S0149-2063(99)00005-7 
Deloitte. (2018). Rising Stars Football Money League. London.

Dietl, H. M., Grossmann, M., \& Lang, M. (2011). Competitive Balance and Revenue Sharing in Sports Leagues With Utility-Maximizing Teams. Journal of Sports Economics, 12(3), 284-308. https://doi.org/10.1177/1527002511404787

Dietl, H. M., Lang, M., \& Rathke, A. (2011). THE COMBINED EFFECT OF SALARY RESTRICTIONS AND REVENUE SHARING IN SPORTS LEAGUES. Economic Inquiry, 49(2), 447-463. https://doi.org/10.1111/j.1465-7295.2010.00330.x

Dobbin, F. (2004). The new economic sociology : a reader. Oxfordshire, UK: Princeton University Press.

Feess, E., \& Stähler, F. (2009). Revenue Sharing in Professional Sport Leagues. Scottish Journal of Political Economy, 56(2), 255-265. https://doi.org/10.1111/j.14679485.2009.00483.x

FIFA. (2018). Global Transfer Market Report: a review of international transfers in 2017. Retrieved from https://www.fifatms.com/wpcontent/uploads/dlm_uploads/2017/01/GTM2017_FIFATMS-1.pdf

Fort, R., \& Maxcy, J. (2003). Competitive balance in complex professional sports leagues. Journal of Sports Economics, 4(2), 154-160. https://doi.org/10.1177/1527002503251641

Fort, R., \& Quirk, J. (2004). Owner Objectives and Competitive Balance. Journal of Sports Economics, 5(1), 20-32. https://doi.org/10.1177/1527002503261275

Fransen, K., Van Puyenbroeck, S., Loughead, T. M., Vanbeselaere, N., De Cuyper, B., Vande Broek, G., \& Boen, F. (2015). Who takes the lead? Social network analysis as a pioneering tool to investigate shared leadership within sports teams. Social Networks, 43, 28-38. https://doi.org/10.1016/j.socnet.2015.04.003

Granovetter, M. (1983). The Strength of Weak Ties: A Network Theory Revisited. 
Sociological Theory. https://doi.org/10.2307/202051

Granovetter, M. (1985). Economic Action and Social Structure: The Problem of

Embeddedness. American Journal of Sociology, 91(3), 481-510.

https://doi.org/10.1086/228311

Granovetter, M. (1992). Economic Institutions as Social Constructions: A Framework for Analysis. Acta Sociologica, 35(1), 3-11. https://doi.org/10.1177/000169939203500101

Granovetter, M. (2005). The Impact of Social Structure on Economic Outcomes. Journal of Economic Perspectives, 19(1), 33-50. https://doi.org/10.1257/0895330053147958

Granovetter, M. (2017). Society and economy : framework and principles. Cambridge, MA:

The Belknap Press of Harvard University Press.

Hambrick, M. E. (2012). Six Degrees of Information: Using Social Network Analysis to Explore the Spread of Information within Sport Social Networks. International Journal of Sport Communication, 5(1), 16-34. https://doi.org/10.1123/ijsc.5.1.16

Hambrick, M. E. (2019). Social network analysis in sport research. Newcastle-upon-Tyne, UK: Cambridge Scholars Press.

Hill, J. R., \& Jolly, N. A. (2017). Revenue Sharing and Player Salaries in Major League Baseball. Journal of Sports Economics, 18(8), 831-849. https://doi.org/10.1177/1527002515609660

Holland, P. W., \& Leinhardt, S. (1976). Local Structure in Social Networks. Sociological Methodology, 7(1976), 1-45.

Jackson, M. O. (2008). Social and economic networks. Princeton, NJ: Princeton University Press.

Jones, G. J., Edwards, M. B., Bocarro, J. N., Bunds, K. S., \& Smith, J. W. (2018). A structural perspective of cross-sector partnerships involving youth sport nonprofit organizations. European Sport Management Quarterly, 18(2), 133-155. 
https://doi.org/10.1080/16184742.2017.1322625

Knoke, D. (2012). Economic networks. Cambridge, UK: Polity Press.

Knoke, D., \& Yang, S. (2008). Social network analysis (2nd Editio). London: SAGE Publications Inc.

Kringstad, M. (2018). Is gender a competitive balance driver? Evidence from Scandinavian football. Cogent Social Sciences, 4(1), 1-15. https://doi.org/10.1080/23311886.2018.1439264

Liu, X. F., Liu, Y.-L., Lu, X.-H., Wang, Q.-X., \& Wang, T.-X. (2016). The Anatomy of the Global Football Player Transfer Network: Club Functionalities versus Network Properties. PLOS ONE, 11(6). https://doi.org/10.1371/journal.pone.0156504

Luce, R. D., \& Perry, A. D. (1949). A method of matrix analysis of group structure. Psychometrika, 14(2), 95-116. https://doi.org/10.1007/BF02289146

Lusher, D., Robins, G., \& Kremer, P. (2010). The application of social network analysis to team sports. Measurement in Physical Education and Exercise Science, 14(4), 211-224. https://doi.org/10.1080/1091367X.2010.495559

Magowan, A. (2015). Premier League: Is the loan system being abused by clubs? - $B B C$ Sport. Retrieved August 13, 2018, from https://www.bbc.co.uk/sport/football/34125476 Naraine, M. L., \& Parent, M. M. (2016). Illuminating Centralized Users in the Social Media Ego Network of Two National Sport Organizations. Journal of Sport Management, 30(6), 689-701. https://doi.org/10.1123/jsm.2016-0067

Neale, W. C. (1964). The Peculiar Economics of Professional Sports: A Contribution to the Theory of the Firm in Sporting Competition and in Market Competition. The Quarterly Journal of Economics, 78(1), 1. https://doi.org/10.2307/1880543

Newman, M. E. J. (2010). Networks : an introduction. Oxfordshire, UK: Oxford University Press. 
Noll, R. G. (2002). The Economics of Promotion and Relegation in Sports Leagues. Journal of Sports Economics, 3(2), 169-203. https://doi.org/10.1177/152700250200300205

Noll, R. G. (2003). The Organization of Sports Leagues. Oxford Review of Economic Policy, 19(4), 530-551. https://doi.org/10.1093/oxrep/19.4.530

Opsahl, T. (2009). Structure and Evolution of Weighted Networks. University of London (Queen Mary College).

Opsahl, T., \& Panzarasa, P. (2009). Clustering in weighted networks. Social Networks, 31(2), 155-163. https://doi.org/10.1016/j.socnet.2009.02.002

Owen, P. D., \& King, N. (2015). Competitive balance measures in sports leagues: The effects of variation in season length. Economic Inquiry, 53(1), 731-744. https://doi.org/10.1111/ecin.12102

Peeters, T. (2015). Profit-maximizing gate revenue sharing in sports leagues. Economic Inquiry, 53(2), 1275-1291. https://doi.org/10.1111/ecin.12184

Quatman, C., \& Chelladurai, P. (2008a). Social Network Theory and Analysis: A Complementary Lens for Inquiry. Journal of Sport Management, 22(3), 338-360. https://doi.org/10.1123/jsm.22.3.338

Quatman, C., \& Chelladurai, P. (2008b). The Social Construction of Knowledge in the Field of Sport Management: A Social Network Perspective. Journal of Sport Management, 22(6), 651-676. https://doi.org/10.1123/jsm.22.6.651

Quirk, J. (1987). Intermediate microeconomic (3rd ed.). Chicago, IL: Science Research Associates, Inc.

Quirk, J., \& Fort, R. (1995). Cross-subsidization, Incentives , and in Professional Team Outcomes Sports Leagues. Journal of Economic Literature, 33(3), 1265-1299.

Ramchandani, G., Plumley, D., Boyes, S., \& Wilson, R. (2018). A longitudinal and comparative analysis of competitive balance in five European football leagues. Team 
Performance Management: An International Journal, 24(5/6), 265-282.

https://doi.org/10.1108/TPM-09-2017-0055

Rockerbie, D., \& Easton, S. (2018). Revenue Sharing in Major League Baseball: The Moments That Meant so Much. International Journal of Financial Studies, 6(3), 71. https://doi.org/10.3390/ijfs6030071

Rotternberg, S. (1956). The Baseball Players' Labor Market. Journal of Political Economy, 64(3), 242-258.

Salancik, G. R., \& Pfeffer, J. (1978). A social information processing approach to job attitudes and task design. Administrative Science Quarterly, 23(2), 224-253.

Sallent, O., Palau, R., \& Guia, J. (2011). Exploring the Legacy of Sport Events on Sport Tourism Networks. European Sport Management Quarterly, 11(4), 397-421. https://doi.org/10.1080/16184742.2011.599208

Schreyer, D., \& Torgler, B. (2018). On the Role of Race Outcome Uncertainty in the TV Demand for Formula 1 Grands Prix. Journal of Sports Economics, 19(2), 211-229. https://doi.org/10.1177/1527002515626223

Scott, J. (2017). Social network analysis (4th Edition). London: SAGE Publications Ltd. Simmons, R. (2007). Overpaid Athletes ? Comparing American and European Football. The Journal of Labor and Society, 10(December), 457-471. https://doi.org/10.1111/j.17434580.2007.00176.x

Stuart, T. E. (1998). Network Positions and Propensities to Collaborate: An Investigation of Strategic Alliance Formation in a High-Technology Industry. Administrative Science Quarterly, 43(3), 668-698. https://doi.org/10.2307/2393679

Szymanski, S. (2016). Revenue Sharing in a Sports League with an Open Market in Playing Talent: A Comment. Theoretical Economics Letters, 06(06), 1337-1340. https://doi.org/10.4236/tel.2016.66123 
Szymanski, S., \& Kesenne, S. (2004). Competitive balance and gate revenue sharing in team sports. Journal of Industrial Economics, 52(1), 165-177. https://doi.org/10.1111/j.00221821.2004.00220.x

Vega-Redondo, F. (2007). Complex Social Networks. Cambridge: Cambridge University Press.

Wäsche, H. (2015). Interorganizational cooperation in sport tourism: A social network analysis. Sport Management Review, 18(4), 542-554.

https://doi.org/10.1016/j.smr.2015.01.003

Wäsche, H., \& Woll, A. (2013). Managing regional sports tourism networks: A network perspective. European Sport Management Quarterly, 13(4), 404-427.

https://doi.org/10.1080/16184742.2013.811608

Wasserman, S., \& Faust, K. (2009). Social network analysis : methods and applications (9th ed.). Cambridge, UK: Cambridge University Press.

Wiegmann, A. (2018). FIFA to limit loan deals from 2020-21 season - report - Reuters.

Retrieved March 26, 2019, from https://uk.reuters.com/article/uk-soccer-fifatransfers/fifa-to-limit-loan-deals-from-2020-21-season-report-idUKKCN1NZ0CV

Wilson, R., Ramchandani, G., \& Plumley, D. (2018). Parachute Payments in English Football: Softening the Landing or Distorting the Balance? Journal of Global Sport Management, 3(4), 351-368. https://doi.org/10.1080/24704067.2018.1441740

Yan, G., Pegoraro, A., \& Watanabe, N. M. (2018). Student-Athletes' Organization of Activism at the University of Missouri: Resource Mobilization on Twitter. Journal of Sport Management, 32(1), 24-37. https://doi.org/10.1123/jsm.2017-0031

Yan, G., Watanabe, N. M., Shapiro, S. L., Naraine, M. L., \& Hull, K. (2018). Unfolding the Twitter scene of the 2017 UEFA Champions League Final: social media networks and power dynamics. European Sport Management Quarterly, 0(0), 1-18. 
https://doi.org/10.1080/16184742.2018.1517272

York, K. M., \& Miree, C. E. (2018). Averting a tragedy of the commons: revenue sharing and competitive balance in the NHL. Sport, Business and Management: An International Journal, 8(1), 35-51. https://doi.org/10.1108/SBM-03-2017-0014

Zimbalist, A. S. (2002). Competitive Balance in Sports Leagues. Journal of Sports Economics, 3(2), 111-121. https://doi.org/10.1177/152700250200300201 